\title{
A comparative study of the effect of web-based versus in-class textbook ethics instruction on accounting students' propensity to whistle-blow
}

\begin{abstract}
This study examined whether accounting students' propensity to whistle-blow differed between those instructed through a web-based teaching module and those exposed to a traditional in-class textbook-focused approach. A total of 156 students from a secondyear financial accounting course participated in the study. Ninety students utilized the web-based module while 66 students were instructed through a traditional teaching approach based on ethical problems presented in the textbook. Subsequently, when presented with a whistle-blowing situation, it was found that students exposed to a webbased ethics instruction module were more likely to whistle-blow than those students exposed to a traditional in-class textbook ethics instruction approach.
\end{abstract}

Keywords: Ethics, whistle-blowing, accounting education, web-based teaching 


\section{Introduction}

For some time it has been recognized that accounting is a socio-technical activity where the values and judgements of accounting practitioners and users of financial information are important (Chow, Shields, \& Wu, 1999; Gernon \& Wallace, 1995; Gray 1988; Jaggi, 1979; Patel, 2003). Financial reporting scandals and criticisms of accountants for their role in the scandals have increased the pressure for ethics training and development in the accounting curriculum. Ethics education has therefore become an important area of teaching for accounting educators (Frank, Ofobike, \& Gradisher, 2010).

Over the years, a number of groups including the National Commission on Fraudulent Financial Reporting (Treadway Commission, 1987) and the American Accounting Association (AAA) (Albrecht \& Sack, 2000) have emphasized the need for integrating ethics into the accounting curriculum. In Australia, a study by the Australian Society of Certified Practising Accountants and the Institute of Chartered Accountants emphasized the importance of whistleblowing as an issue for the profession (ASCPA \& ICAA, 1994). More recently, PricewaterhouseCoopers, based on its study of accounting curriculum within the tertiary sector in 2003, rebuked accounting educators for failing to coherently include ethics as part of the curriculum (Hass, 2005). Further, the American Assembly of Collegiate Schools of Business (AACSB) and the American Institute of Certified Public Accountants (AICPA, 1998) recommended that accounting students should receive ethics education at both the general education and the individual accounting course levels (Thomas, 2004). According to a survey of 17 US CPA firms by Warth (2000), most firms within the sample relied on colleges to teach the ethical behavior expected in the profession.

Whistle-blowing is an important topic because it contributes to improvements in internal control systems (Hooks, Kaplan, \& Schults, 1994). Despite its importance, very little attention in accounting research has been paid specifically to whistle-blowing, which makes it a difficult topic 
to research, and test. Researchers can only examine behavioral intentions instead of the actual behavior of respondents. The present study examined the differences in accounting students' ethical intentions based on the type of ethics instructional approach. Prior studies on accounting students' ethical decision-making have largely focused on the influence of factors such as the type of ethical dilemma e.g. tax evasion versus cheating in exams (O’Leary \& Radich, 2001); the country of origin e.g. Ireland versus Australia (O’Leary \& Cotter, 2000); and gender (Haswell \& Jubb, 1995; O’Leary \& Radich, 2001). There has been no study found that has undertaken an analysis of the effects of different types of teaching approaches utilized by accounting educators on accounting students' ethical judgements.

Traditionally, some of the common tools used for providing ethics awareness in accounting include ethics cases and scenarios within textbooks, professional codes of conduct, instructional videos, games, educational novels and controversial films (Berger \& Pratt, 1998; Haywood, McMullen, \& Wygal, 2004; Madison, 2001). With increasing technological and multimedia developments, there are significant opportunities to adopt more flexible accounting interactive educational tools in the classrooms that are more efficient and effective to improve students' learning outcomes (Byrne, 2002; Huang \& Cappel, 2005; Liu, Lin, \& Wang, 2003). As well, universities are increasingly forced to reconsider their traditional pedagogical learning approaches against more flexible and stimulating web-based approaches (Browning, Gerlich, \& Westermann, 2011; Jonassen, Peck, \& Wilson, 1999). However, the impact of the use of more sophisticated educational resources and approaches, namely one that is web-based, remains indeterminate. Much of the related literature in this area tends to be largely descriptive, focusing on explaining the design of educational resources rather than assessing the outcomes of the adoption of such resources.

The objective of this study was to assess whether the ethical judgements of accounting students differ between those instructed through a web-based, multi-media orientated teaching 
module and those instructed using an in-class textbook-focused approach. The web-based module developed for this study was an innovative learning module specifically designed to develop accounting students' ethical decision-making ability through a systematic integration of the theory of ethics with ethical decision-making models and other decision aids such as the accounting code of professional conduct. Students were also given examples of real-life and hypothetical accounting ethical dilemmas to develop their ethical reasoning and decision-making. It is argued that the key strengths of the module lie in two areas: (a) its more holistic approach to communicating the importance of ethics; how ethical situations can be analysed; and what guidelines are provided by the codes of professional conduct, and (b) in the adoption of a more interesting and interactive teaching format using multimedia tools. Unlike a more traditional educational approach to accounting ethics largely focusing on identifying ethical dilemmas and possible courses of action at the end of the textbook chapters, an interactive web-based module is seen to offer a more rigorous, stimulating and effective learning tool.

The next section of the paper provides a literature review on students' ethical decisionmaking, followed by a description of the accounting tools available to educators for providing ethics awareness education, and the background on the web-based module developed for this study. The research hypothesis is subsequently developed and the research method is described. Following this the results of the study are provided; the findings and implications of the results are discussed; and the conclusion and limitations of the study are delineated.

\section{Literature Review}

While a number of early studies have indicated the impact of ethics education on students' ethical judgements is negligible, more recent studies have provided a positive association between the two factors (Sisaye, 2011). For example, Martin (1981-82) found that enrolment in two ethics 
courses (offered by a department of philosophy) was not significantly related to the ability of students to assess various ethical scenarios. In contrast, Boyd (1981-82) found that compared to students not enrolled in an ethics course, those who were showed improvements in their moral reasoning judgements. Green and Weber (1997) demonstrated that accounting students showed a higher level of moral reasoning ability after taking an auditing course that emphasised the AICPA's code of professional conduct.

Based on a study of the effects of students' exposure to a business ethics course, Gautschi and Jones (1998) found that enrolment in such a course enhances students' ability to recognize ethical issues in business situations. Clikeman and Henning (2000) surveyed 141 college sophomores (56 accounting majors and 77 other business majors) and found no significant differences between the two groups in their willingness to "manipulate earnings". A repeat survey of the same students in their senior year (two years later) revealed that accounting majors were less willing to manipulate earnings than other business majors. These results suggest that accounting education tends to promote greater ethical awareness of professional responsibility and that accounting students with ethics education may start adopting the attitudes of their professional reference groups even before they have commenced their professional careers.

Given that ethical dilemmas in the business world are generally complex, accounting educators need to raise the awareness of such issues among students who ultimately progress to function as accounting professionals. Also, it is vital to cultivate the students' ability to critically evaluate a situation from multiple viewpoints before arriving at a decision that reflects the most ethical course of action (Sims \& Felton, 2006; Ferrell \& Ferrell, 2008). To date, the integration of ethics education in an undergraduate business curriculum has been undertaken in two main ways (Bosco, Melcharr, Beauvais, \& Desplaces, 2010; Waples, Antes, Murphy, Connolly, \& Mumford, 2008). The first approach has involved undertaking a separate and distinct course or subject on 
ethics, usually lasting one semester, covering the foundations of ethics theory and the introduction to various ethical decision-making models. In the Procardio-Foley and McLaughlin (2003) survey of 24 American colleges and universities, it was found that $29 \%$ of the institutions required a business ethics course for their accounting/business majors, and of the remainder, $42 \%$ had a business ethics course that a student could undertake as an elective. The second approach to ethics awareness education has involved incorporating ethical issues or case scenarios in the different courses of an accounting major (Bosco et al., 2010). Often, students are introduced to specific issues at the end of each topic or textbook chapter, and are required to discuss these questions as part of their classroom activity. Each approach has strengths and weaknesses.

The first approach - the use of a distinct ethics course, provides quite a comprehensive and intensive period of ethics study by encompassing the theoretical foundations of ethics; the application of decision-making models; and ethical resolution techniques. However, given the increasing pressure on meeting professional accreditation requirements, undergraduate accounting programs have had difficulty in incorporating a distinct, semester-long ethics course as part of their formal accounting study program (Procario-Foley \& McLaughlin, 2003).

In contrast, the second approach tries to avoid the time problem by integrating and highlighting ethical issues specific to the individual courses as part of the normal accounting course structure. An advantage of this approach is that students can develop a more in-depth understanding of ethical matters in each individual course, and over time across multiple accounting courses in a more sequential mode over the entire accounting program.

Two recent studies reported innovative approaches to providing ethical education to accounting students. First, Haywood et al.’s (2004) study reports on the use of games as a strategy to provide ethical awareness and professionalism to students. In the format of a bingo game with the 
aid of Power Point slides showing examples of (un) ethical practices as reported in the press, students were required to earn spaces on their bingo card by responding appropriately to the ethical issues raised in the slides. The effectiveness of this learning strategy was not measured in terms of the students' ability to make ethical decisions, but was based on student feedback on their perceptions of the games. The general feedback was that it was a fun and stimulating way to learn.

In the second study, Smith, Smith, and Mulig (2005) utilized a computerized Power Point slide show to teach ethics in 10 upper-level business classes. According to Smith et al. ethics is an appropriate topic for a multimedia application for at least two reasons. First, even though recent corporate scandals have highlighted the importance of ethics, there is limited coverage of ethics topics in accounting textbooks. Second, "ethics lends itself to multimedia as there are many images (and music) that stimulate consideration of ethical issues” (Smith et al., 2005, p. 157). The study involved 276 students in a pre-presentation and post-presentation survey. The results suggested that the students' attitudes towards the presentation slides were positive, and that their attitudes towards ethics in general had improved.

There has been no study found in accounting ethics education that examines the impact of adopting a more technologically advanced learning approach encapsulating interactive multimedia with a web-based format.

\section{Hypothesis}

The review of the literature has highlighted the potential for the use of multimedia in teaching and to engage students and stimulate learning. While the term 'multimedia' may commonly mean different things to different people, in the present study it was broadly defined as "the presentation of material in more than one form that undertakes a learner-centred approach”. This includes the use 
of words, pictures, sounds and various interactive tools while taking into consideration that students' learning styles may differ. Support for the use of multimedia learning is premised on the idea that instructional messages should be designed in light of how the human mind works (Mayer \& Chandler, 2001). While some textbooks have colorful diagrams and illustrations, it is argued that seeing, hearing and interacting with instructional messages might reinforce the information more strongly and lead to better learning outcomes (Miller, 1996; Smith et al., 2005). It has been suggested that presenting an explanation with words and pictures results in better learning than presenting words alone (Mayer \& Gallini, 1990; Mayer \& Sims, 1994). Therefore a multimedia approach to ethics instruction could prove more engaging, reinforce the importance of ethics and help students make more ethical decisions. Therefore it is hypothesised that,

H1: There is a statistically significant difference in the ethical judgements made between accounting students exposed to a web-based, multimedia ethics learning module and those exposed to a textbook-focused learning approach.

\section{Method}

\section{Participants}

This study involved a total of 156 second-year financial accounting students from two Australian universities (A and B), located within a radius of 100 kilometers. Student cohort A (90) received instructions via the web-based module that was available to students through their course website, while student cohort B (66) was exposed to ethical situations through an in-class textbook instructional approach. Both instruction methods were similar in context (a description of the instruction methods is provided in Instructional Delivery section below). The students' ethical judgements were assessed at the end of a 13-week study semester through a questionnaire survey involving a whistle-blowing case scenario, therefore only the responses of students attending the 
final lecture were included. Students who had received any prior ethics instruction were removed from the analysis.

\section{Research Design}

As the study was designed to explore differences in ethical attitudes between two student cohorts, an appropriate design would have seen the cohort of students at one university randomly split into two groups, with one researcher instructing each group. One group would have their ethics instruction conducted using the interactive learning module while the other group would be instructed using the more traditional textbook method. Unfortunately, permission was not granted to provide two different instruction methods to the same university cohort, therefore the study was designed to examine two cohorts across two universities. Two of the study's researchers were the instructors for these courses. As similar texts were assigned, the same topics and assessment pieces covered (mid-semester exam, assignment and final exam) it was considered appropriate to conduct the study across the two universities. Further, the two student cohorts were also similar in age, gender breakdown, previous work experience and education and had a comparable domestic/international student representation.

Additionally, the research design raises two issues in relation to the participants and the methods adopted. While the authors, based on their experience in teaching these two cohorts, have no reason to believe that the ethical orientation was different between the two, as a pre-test was not conducted (due to unplanned and unforeseen circumstances), no definite proof can be provided. It is argued herein that based on the teaching experience of the authors, closeness in location of the two universities in terms of student population catchment and the similar characteristics of the two cohorts, it is probable that the ethical orientation of the two cohorts was also similar. This is considered a limitation of the study and is further addressed in the final section of the paper. Additionally, as two different instructors (two of the authors) taught each of the cohorts, it is 
possible that there was an impact upon students' ethical decisions due to differences in teaching styles. To minimize differences in teaching across the two groups, the instructors/researchers were in constant contact over the course of the semester, particularly during the ethics instruction.

The survey was pilot-tested by six accounting academics and four third-year accounting major students. The pilot test was undertaken to provide confidence that the survey questions were unambiguous and clear and would be understandable to the respondents. No major issues were identified except for some minor formatting changes requested.

Multiple regression analysis was conducted to test the research hypothesis. Multiple regression analysis was chosen as the method to analyze the data as it enables the testing of each of the hypotheses based upon the significance levels of the standardized coefficients. While the sample size is not large, it is considered sufficient for the multiple regression technique with greater than the minimum suggested size of 5 per independent variable (Tabachnich \& Fiddell, 2010).

Additionally, multiple regression analysis enables a more rigorous test of the relationship between the dependent (ethical judgement) and the independent variables (ethics instructional method) by allowing the inclusion of personal characteristic variables to control for gender, age and international status.

\section{Procedure}

Both the web-based ethics module and the in-class approach were guided by Rest’s (1979) ethical behavior model, which involves four key components:

1. Ethical sensitivity (identifying the issues or conflicts).

2. Ethical reasoning (rationalizing the situation).

3. Ethical motivation (desire to act ethically).

4. Ethical behaviour (acting or carrying through). 
According to Rest (1979), an individual can demonstrate ethical behavior only if he is able to recognize that an ethical conflict or issue exists in a given situation. The individual then needs to analyze the various implications of the available choices of action, be motivated to act in the most ethical manner, and to act according to his or her intentions.

Accounting educators can play a key role in enhancing the first three components, with the final outcome - an individual's actual ethical behavior - remaining a function of his or her will. Ethical sensitivity can be enhanced in accounting courses by discussing the issues germane to the technical issues being covered. Accounting academics can still play an important role in motivating students to act ethically or 'do the right thing'.

The Web-based Ethics Module. The educational resource adopted in this study is an interactive, web-based module using a multimedia format. The researchers developed the webbased module with the assistance of a web designer. The researchers developed the content and designed the module, page by page, while the web designer created the module based on the researchers' instructions.

A multi-dimensional approach was adopted towards developing the ethical decision-making ability of the students whereby a comprehensive set of learning features including exposure to ethical theories, ethical decision-making frameworks and practise application problems were adopted. More specifically, the module comprised the following main sections:

1. Importance of ethics for accountants.

2. Ethical theories.

3. Ethical decision-making model.

4. Professional Code of Conduct.

5. Ethical Scenarios in Financial Accounting.

In the web-based model, a brief overview of the three main normative ethical perspectives, namely deontology, teleology and virtue ethics was provided (Gay \& Simnett, 2000). Several 
interactive problems in a multiple-choice format were used where students learned to distinguish the outcomes of adopting each of the ethical rationales or perspectives in a given ethical situation. Many of the ethics cases and problems at the end of textbook chapters usually aim to help foster ethical sensitivity. In this study, the web-based module went further by including hypothetical examples of ethical scenarios from a financial accounting perspective and provided additional links to reports on the Internet, namely high profile real-life cases such as WorldCom and One-Tel in the section on ethical scenarios.

The web-based module was first introduced to students in the lecture of week three of a 13week teaching semester, and students were therefore able to use the web-based module throughout the remaining 10-week semester period. The introductory lecture involved a 45-minute discussion of a case study where various issues were raised that related to the relevant components of the webmodule. As well, ethical situations formed part of their weekly tutorial homework and students were then regularly encouraged to use various components of the ethics module throughout the semester.

The In-Class Textbook Method. Cohort B students were exposed to the in-class textbook educational mode. Weeks one and two of instruction were comprised of explaining the importance of ethics for accountants; ethical theories; and providing and explaining professional codes of conduct. In week three, an ethical decision-making model was introduced together with a case study-type question. This was put to the student cohort and a question and answer session followed where students were encouraged to discuss the issues raised in the case using the decisionmaking model as a guide. Following this, students were given ethical problems in the proceeding tutorial of a similar nature (questions relating to ethical situations were largely taken from the textbook) and were asked to solve or debate the particular issue at hand on an individual basis. Students were expected to complete the analysis of the nominated ethical problems prior to the tutorial. These answers were then brought to the student's tutorial and discussed as a group, 
enabling students to provide their own view on the problem and how it was solved, and listen to other students’ perceptions and solutions.

Following the individual presentation of solutions to the tutorial homework, an additional problem was given to students in the tutorial class where they were asked to form groups to debate and solve the ethical dilemma. Once again, students listened to the solutions given by groups. It was noticed that individual solutions to problems were often more 'extreme' or 'hard-line' as opposed to group solutions. In the subsequent weeks, an ethical situation pertinent to each week’s topic (based on an example from the textbook) was raised and discussed during lectures. Individual homework relevant to an ethical problem was also set each week, and additional in-class problems were introduced and discussed.

\section{Variable Measurement}

The survey questionnaire consisted of an ethical scenario relating to a whistle-blowing situation, and 11 related questions that assessed the respondent's ethical judgement or decisionmaking. A copy of the whistle-blowing scenario and the related questions are provided in Appendix A. The whistle-blowing scenario was based on a case developed by Meier and Rittenberg (1986) and subsequently used by Arnold and Ponemon (1991) and Patel (2003). The questions requested of the respondents are based on the Reidenbach and Robin’s (1990) multi-dimensional ethical judgement scale. Three single-attribute questions were included that asked respondents to evaluate the scenario in terms of whether the decision made was ethical (scale of 1) or unethical (scale of 8) (ETHICAL), whether they would make the same decision $(1=$ highly probable; 8 = highly improbable) (SAMEDEC), and whether their colleagues would make the same decision (1 = highly probable; 8 = highly improbable) (COLLDEC). Further, eight additional items were also included measuring respondents' judgement of moral equity, relativism and contractualism. Moral equity which is premised on justice theory is related to the four attributes: fair/unfair, just/unjust, morally 
right/not morally right, and acceptable/unacceptable (rated on a 1-8 scale). The measure of moral equity was calculated as the average of the above four attributes (MORALEQ). The concept of relativism, which assumes that all values are a function of culture (Singer, 1994), was composed of the two items: culturally acceptable/unacceptable, and traditionally acceptable/unacceptable (rated on a 1-8 scale), while contractualism was measured by the two items: Does not violate/violates an unwritten contract, and Does not violate/violates a spoken promise (rated on a 1-8 scale). The theoretical basis for contractualism is rooted in the philosophy of deontology with the focus on the importance of ethics in social contracts (Kohlberg, 1984). The measures of the relativism and contractualism (RELATIV and CONTRACT, respectively) were calculated as the average of the two relevant variable items. All responses were sought on an eight-point bipolar scale and the greater the value, the more unethical/unfair/unjust/not morally right etc., respondents viewed the case scenario decision to not whistle-blow. In addition, participants were asked several background questions such as age, gender, work experience, previous ethics instruction and educational qualifications.

\section{Results}

The descriptive statistics of the participants are presented in Table 1. Student cohort A and student cohort B were similar in terms of age, work experience and number of years in full-time and part-time work. The breakdown of the two cohorts regarding gender and higher education level attained slightly differ. Approximately $46 \%$ of cohort A was male and 54\% was female, whereas $40 \%$ of cohort B was male and $60 \%$ was female. In addition, a larger percentage of students from cohort B had completed prior tertiary/university study (37\% compared to $21 \%$ from cohort A).

\section{Insert Table 1 here}


The descriptive statistics of the whistle-blowing scenario survey questionnaire items are presented in Table 2. Statistics are provided for both cohort A and cohort B. Overall, the average response to each question was above the mid-point of the eight-item bipolar scale for student cohort A and below the mid-point for student cohort B. Therefore, students from cohort A who were exposed to the web-based interactive teaching module were more likely to engage in whistleblowing than students from cohort B who were exposed to the in-class textbook-based teaching approach.

\section{Insert Table 2 here}

Independent samples $t$-tests were conducted to test for differences between each cohort's response to the ethical judgement questions relating to the whistle-blowing scenario. The results of these tests are presented in Table 3.

As shown in Table 3, the differences in the mean responses of cohort A and cohort B were statistically significant for all eleven questions, with cohort A providing significantly greater ethical responses to all questions than cohort $\mathrm{B}$ ( $p<0.05$ for all questions). This finding is particularly important for 'you would make the same decision' and 'your colleague would make the same decision', which provides the strongest test of the research hypothesis (Patel, 2003). Further, as the difference in the scores for these two questions was positive and significant, this indicates that student cohort A was more likely to engage in whistle-blowing than student cohort B $(p<0.001)$.

\section{Insert Table 3 here}


The research hypothesis was tested by separately fitting each of the six dependent variables to the following equation that includes three control variables of gender, age and student international status:

$$
Y=b_{1}+b_{2} \mathrm{ETHMODE}+b_{3} \mathrm{GENDER}+b_{4} \mathrm{AGE}+b 5 \mathrm{STUD}+e
$$

where:

$$
\begin{aligned}
Y & =\text { ETHICAL = how ethical would you rate the decision; or } \\
& =\text { MORALEQ = moral equity; or } \\
& =\text { RELATIV = relativism; or } \\
& =\text { CONTRACT = contractualism; or } \\
& =\text { SAMEDEC = would you make same decision; or } \\
& =\text { COLLDEC = would your colleagues make same decision } \\
\text { ETHMODE } & =\text { ethics instructional mode } \\
& \text { ("0" = in-class textbook method; " } 1 \text { " = web-based ethics module) } \\
\text { GENDER } & =\text { gender } \\
\text { AGE } & \text { (“0” = male; "1" = female) } \\
\text { STUD } & =\text { age } \\
& \text { (“0” }
\end{aligned}
$$

Results of the regression analyses are presented in Table 4. Five of the six regression equations were statistically significant ( $p<0.00$ for all equations) having adjusted $R^{2}$ s ranging from $13.2 \%$ to $59.2 \%$ (the COLLDEC regression equation was non-significant). Instructional mode was significantly positive in all equations $(p<0.00)$ suggesting that, holding gender, age and student status constant, students who were part of the web-based ethics instruction group were less likely to make the same decision to not whistle-blow $(p<0.000)$. Furthermore, the results suggest that students who received the web-based instruction evaluated the case scenario decision to not whistle-blow as unfair, unjust, not morally right, unacceptable to their family, culturally unacceptable, traditionally unacceptable, violating an unwritten and unspoken social contract (all coefficients $p<0.000)$. Interestingly, domestic students $(p<0.005)$ who received the web-based ethics instruction $(p<0.000)$ were more likely to rate the decision as unethical. 


\section{Insert Table 4 here}

Overall, it can be concluded that the accounting students exposed to the multimedia, webbased ethics learning module made more ethical judgements (i.e. more likely to whistle-blow) than those exposed to the in-class textbook-focused learning module. The hypothesis is therefore supported.

\section{Discussion}

Extant literature indicates that commonly used tools in ethical education in accounting ethics range from basic textbooks and professional articles to electronic resources such as firm and internet websites (Browning et al., 2011; Thomas, 2004). Rest’s (1979) ethical behavior model was used to develop the ethic content of the courses, which takes into consideration the need to first increase student awareness of the existence of an ethical problem or issue, followed by developing their ability to rationalize the situation and encourage the desire to act ethically, leading to ethical judgements and decisions. The results of this study indicate that the ethical judgement of accounting students tends to be higher among those instructed through the web-based module when compared with students who were instructed through the traditional in-class textbook-focused method. These results suggest that a more stimulating, flexible and visually attractive electronic module is more effective in affecting the ethical judgements of accounting students (Bosco et al., 2010; Saat, Porter, \& Woodbine, 2010). The results also provide support for Smith et al. (2005) who contends that ethics lends itself to multimedia as the various ethical issues can be made more interesting and relevant to students It is suggested that exposure to the fundamentals of ethics theory, ethical decision models including the code of professional conduct for accountants using a multidimensional media approach, is more effective to enhancing ethical judgements of accounting students than the in-class textbook method that provides these fundamental tools. 
An additional implication of the study was the difference between individual and group responses for those students in cohort B, the in-class learning approach group. Although not specifically tested, it is worth noting that views discussed and presented as a group were less extreme, although more thoroughly investigated than those presented individually. Cohort A did not discuss problems on a group basis, but dealt with them individually. O’Leary and Pangemanan (2007) found that groups displayed stronger tendencies to take safer or neutral routes, while individuals displayed stronger opinions and were more inclined to take extreme actions such as whistle-blowing. This was attributed to factors such as interaction between group members having a greater pool of abilities and insights, increased error checking and quality control, eliciting and provoking new thoughts. This may be a confounding factor in this study, as there were no 'group' dynamics with respect to hearing and understanding alternative views for cohort A. Although student cohort A appeared to make significantly greater ethical decisions with respect to whistleblowing, is it ethical behaviour or strong individual opinion overriding well-thought-out debated action? Further study in-group dynamics with respect to whistle-blowing and ethical dilemmas may be warranted to gain a better understanding of more effective design of such web-based modules.

\section{Recommendations}

The results of this study lead to several implications for accounting ethics education. The study extends the literature and provides evidence to educators on the need for more innovative web-based educational tools to be developed, rather than adopting traditional in-class textbook methods. From a practical viewpoint, the results of this study have implications for developing more effective ethics education tools for accounting students. 
Apart from the usual shortcomings associated with survey research, some additional limitations of the study should be acknowledged. First, generalizability of the findings to all accounting students should be undertaken with some caution due to self-selection of respondents. Only students who attended the final lecture in both student cohort A and B were included in the study. This may raise issues in relation to motivation and any impact this may have on students' responses to the survey questions. Secondly, generalizability of the results would be improved if additional potential confounding variables, such as religious background and multiple instructors (as discussed above) were controlled for in the study, as well as the differing practices of both cohort A and B with respect to group decision-making. Finally, a stronger research design would result if a measure of students' ethical orientation had been undertaken prior to exposure to the ethics instruction. A baseline measure would provide useful insights into the progressive impact of the modes of ethics instruction upon students' ethical judgements.

A number of avenues for further research should be noted. As discussed, culture may have a moderating effect on students' ethical decision-making and as such is worthy of further study. The impact of interactive, visually stimulating multimedia methods of instruction on males and females also warrants further study. In addition, a longitudinal study that incorporates multiple exposures to web-based ethics instruction over time, including group discussions, would provide even greater insights into the impact of interactive multimedia instruction methods on students' ethical judgements. 


\section{Appendix A}

Sam has been an internal auditor for seven years with an organization that is a primary contractor for the Australian Government. Sam recently completed an audit of a subsidiary business unit (ABC plant) that is completing large contracts for various government agencies. The billings of the subsidiary have been audited previously with no major problems detected. During the present audit, Sam discovered, within the subsidiary's billing system, a series of bogus (inflated or falsified) invoices to customers that had already been paid. Sam reported this finding to the director of internal audit. The director said that he would report it to authorities within the company. After a few days, the director told Sam, "forget about it”. Sam argued that further action should be taken but the director shouted, "if you pursue this, you will be fired".

Sam is aware that finding another well-paid position in the current economic climate is going to be difficult. After thinking about this for a few days, Sam decided not to report the matter to the next higher level of management.

Q1: How would you evaluate Sam's decision? Please indicate your evaluation of Sam's decision by marking a cross $(\boldsymbol{X})$ on a specific point on each of the following scales.

(a) Ethical

(b) Fair

(c) Just

(d) Morally right

(e) Acceptable to my family

(f) Culturally acceptable

(g) Traditionally acceptable

(h) Does not violate an unwritten social contract

(i) Does not violate an unspoken social contract
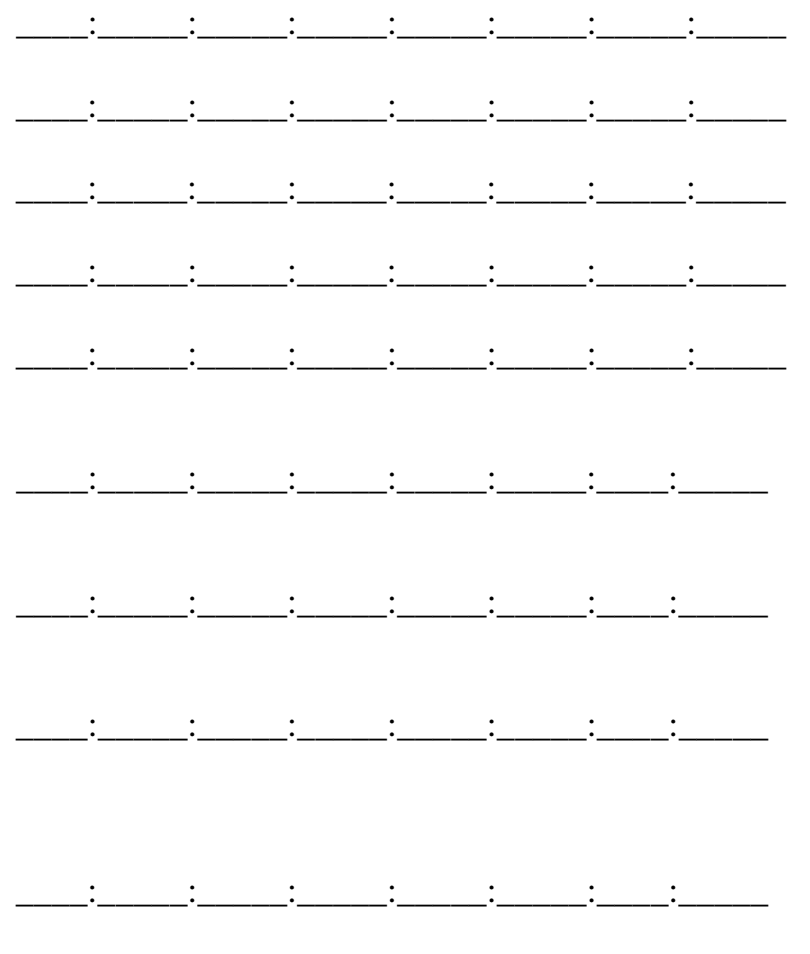

Unethical

Unfair

Unjust

Not morally right

Unacceptable

to my family

Culturally unacceptable

Traditionally unacceptable

Violates an unwritten social contract

Violates an unspoken social contract

Q2: If you were responsible for making the decision in the above case, what is the probability that you would make the same decision as Sam?

Highly Probable

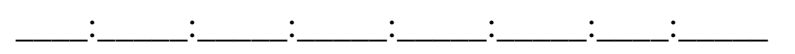
Highly Improbable

Q3: If your colleagues were responsible for making the decision in the above case, what is the probability that they would make the same decision as Sam?

Highly Probable

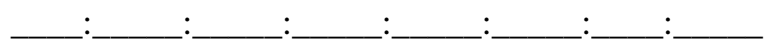

Highly Improbable 


\section{References}

AICPA. (1998). The supply of accounting graduates and the demand for public accounting recruit. New York, NY: AICPA.

ASPCA \& ICAA. (1994). The Middleton Report. Sydney, NSW: ASPCA.

Albrecht, W.S., \& Sack, R.J. (2000). Accounting education: Charting the course through a perilous future. Sarasota, Florida: American Accounting Association.

Arnold, D.F., Sr \& Ponemon, L.A. (1991). Internal auditors’ perceptions of whistle-blowing and the influence of moral reasoning: an experiment. Auditing: A Journal of Practice and Theory, 10, $1-15$.

Berger, J. \& Pratt, C.B. (1998). Teaching business communication ethics with controversial films. Journal of Business Ethics, 17, 1817-1823.

Bosco, S.M., Melchar, D.E., Beauvais, L.L., \& Desplaces, D.E. (2010) Teaching business ethics: the effectiveness of common pedagogical practises in developing students’ moral judgement competence. Ethics and Education, 5, 263-280.

Boyd, D.P. (1981-1982). Improving ethical awareness through the business and society course. Business and Society, 20 and 21, 27-31.

Browning, L., Gerlich, R.N., \& Westermann, L. (2011). The new HD classroom: A "hyper-diverse” approach to engaging with students. Journal of Instructional Pedagogies, 5, 1-10.

Byrne, R. (2002). Web-based learning versus traditional management development methods. Singapore Management Review, 24, 59-68.

Chow, C.W., Shields, M.D., \& Wu, A. (1999). The importance of national culture in the design of and preferences for management controls for multi-nationals' operations. Accounting, Organizations and Society, 24, 441-461. 
Clikeman, P.M., \& Henning, S.L. (2000). The socialization of undergraduate accounting students. Issues in Accounting Education, 15, 1-17.

Frank, G., Ofobike, E., \& Gradisher, S. (2010). Teaching business ethics: a quandary for accounting educators. The Journal of Education for Business, 85, 132-138.

Ferrel, O.C., \& Ferrell, L. (2008). A decision-making framework for business ethics education. In D.L. Swanson \& D.G. Fisher (Eds.), Advancing Business Ethics Education. USA: Interaction Age Publishing.

Gautschi III, F.H., \& Jones, T.M. (1998). Enhancing the ability of business students to recognize ethical issues: An empirical assessment of the effectiveness of a course in business ethics. Journal of Business Ethics, 17, 205-216.

Gay, G., \& Simnett, R. (2000). Auditing and assurance services in Australia. Sydney, NSW: Irwin/McGraw-Hill.

Gernon, H., \& Wallace, R. (1995). International accounting research: A review of its ecology, contending theories and methodologies. Journal of Accounting Literature, 14, 54-106.

Gray, S. (1988). Towards a theory of cultural influence on the development of accounting systems internationally. Abacus, 24, 1-15.

Green, S., \& Weber, J. (1997). Influencing ethical development: Exposing students to the AICPA code of conduct. Journal of Business Ethics, 16, 777-790.

Hass, A. (2005). Now is the time for ethics in education. CPA Online Journal, 75. Retrieved from http://www.nysscpa.org/cpajournal/2005/605/essentials/p66.htm

Haswell, S., \& Jubb, P. (1995). Unethical tendencies. Charter, 66, 102-105.

Haywood, M.E., McMullen, D.A., \& Wygal, D.E. (2004). Using games to enhance student understanding of professional and ethics responsibilities. Issues in Accounting Education, 19, 85-99. 
Hooks, K., Kaplan, S., \& Schultz, J. Jr (1994). Enhancing communication to assist in fraud prevention and detection. Auditing: A Journal of Practice and Theory, 13, 86-117.

Huang, Z., \& Cappel, J.J. (2005). Assessment of a web-based learning game in an information systems course. The Journal of Computer Information Systems, 45, 42-49.

Jaggi, B. (1979). The impact of the cultural environment on financial disclosures in Notable Contribution to the Periodical International Accounting Literature - 1975-78. Sarasota, Florida: American Accounting Association.

Jonassen, D.H., Peck, K.L., \& Wilson, B.G. (1999). Learning with technology. A constructivist perspective. Upper Saddle River, NJ: Prentice Hall.

Kohlberg, L. (1984). The psychology of moral development: Volume 2. San Francisco, CA: Harper and Row.

Liu, Y., Lin, F., \& Wang, X. (2003). Education practice and analyzing behavior of students in a webbased learning environment: An exploratory study from China. Online Information Review, 27, 110-119.

Madison, R.L. (2001). To what extent is ethics taught in the accounting programs of Ohio's colleges and universities? The Ohio CPA Journal, April-June, 39-42.

Martin, T.R. (1981-1982). Do courses in ethics improve the ethical judgement of students? Business and Society, 20 and 21, 17-26.

Mayer, R.E. \& Chandler, R. (2001). When learning is just a click away: Does simple user interaction foster deeper understanding of multimedia messages? Journal of Education Psychology, 93, 390-397.

Mayer, R.E., \& Gallini, J.K. (1990). When is an illustration worth ten thousand words? Journal of Educational Psychology, 82, 715-726. 
Mayer, R.E., \& Sims, V.K. (1994). For whom is a picture worth a thousand words? Extensions of a dual-coding theory of multimedia learning. Journal of Educational Psychology, 86, 389-401.

Meier, M., \& Rittenberg, L. (1986). Dealing with known corporate wrong-doing. The Internal Auditor, April, 37-39.

Miller, L.C.H. (1996). Understanding the effects of a multimedia presentation's sequencing strategy on learning: an experimental investigation. Published PhD dissertation, Texas: A and M University.

O’Leary, C., \& Pangemanan, G. (2007). The effect of groupwork on ethical decision-making of accountancy students. Journal of Business Ethics, 75, 215-228.

O’Leary, C., \& Cotter, D. (2000). The ethics of final year accountancy students: An international comparison. Managerial Auditing Journal, 15, 108-115.

O’Leary, C., \& Radich, R. (2001). An analysis of Australian final year accountancy students' ethical attitudes. Teaching Business Ethics, 5, 235-249.

Patel, C. (2003). Some cross-cultural evidence on whistle-blowing as an internal control mechanism. Journal of International Accounting Research, 2, 69-96.

Procario-Foley, E.G., \& McLaughlin, M.T. (2003). A propaedeutic for a framework: Fostering ethical awareness in undergraduate business students. Teaching Business Ethics, 7, 279-301.

Reidenbach, R.E., \& Robin D.P. (1990). Toward the development of a multi-dimensional scale for improving evaluations of business ethics. Journal of Business Ethics, 9, 639-653.

Rest, J. (1979). Development in judging moral issues. Minneapolis: University of Minneapolis Press.

Saat, M.M., Porter, S., \& Woodbine, G. (2010). The effect of ethics courses on the ethical judgementmaking ability of Malaysian accounting students. Journal of Financial Reporting and Accounting, 8, 92-109. 
Sims, R.R., \& Felton Jr, E.L. (2006). Designing and delivering business ethics teaching and learning. Journal of Business Ethics, 63, 297-312.

Singer, J. (1994). Ethics. Oxford, UK: Oxford University Press.

Sisaye, S. (2011). The functional-institutional and consequential-conflictual sociological approaches to accounting ethics education: integrations from sustainability and ecological resources management literature. Managerial Auditing Journal, 26, 236-294.

Smith, L.M., Smith, K.T., \& Mulig, E.V. (2005). Application and assessment of an ethics presentation for accounting and business classes. Journal of Business Ethics, 61, 153-164.

Thomas, C.W. (2004). An inventory of support materials for teaching ethics in the post-Enron era. Issues in Accounting Education, 19, 27-52.

Treadway Commission (1987). Report of the national commission on fraudulent financial reporting. USA.

Waples, E.P., Antes, A.L., Murphy, S.T., Connelly, S., \& Mumford, M.D. (2010). A meta-analytic investigation of business ethics instruction. Journal of Business Ethics, 87, 133-151.

Warth, R.J. (2000). Ethics in the accounting profession: A study. CPA Journal, 70, 69-70. 